\title{
Jogo Educativo com Tema Histórico: Fundação da Cidade de Marabá-PA, e o Ciclo Econômico do Caucho.
}

\section{Rangel Filho Teixeira, Gilberto Pinheiro Oliveira, Lavoizie Carvalho Guimarães, Tiago de Souza Araújo, Manoel Ribeiro Filho}

\author{
Faculdade de Computação e Engenharia Elétrica - Universidade Federal do Sul e \\ Sudeste do Pará (Unifesspa) - 68501-970 - Marabá - PA - Brazil \\ \{rangel.filho, Gilberto.oliveira, lavoizie, tiagobethel, \\ manoelrib\} @unifesspa.edu.br
}

\begin{abstract}
This paper presents an educational game with historical theme about the foundation of Marabá city, in Pará state, and its first economic cycle, the rubber cycle. The game has two phases: Phase 1 occurring in the Pontal area (between of Itacaiunas and Tocantins rivers), where the mission will be reforested with trees of rubber; and phase 2 that occurs in the between of the streets 27 de Março and Quintino Bocaiuva, where the mission will be to build a new "Casa Marabá". Throughout the game will have as main objective to obtain "information bonus." The game development process is described, highlighting the educational and entertaining aspects, as well as the results of using the game by students of various classes of 8th year of basic school in Amazonian Studies discipline, which is part of schools curriculums of Pará state.
\end{abstract}

Resumo. Esse artigo apresenta um jogo educacional com tema histórico sobre a fundação da cidade de Marabá, no estado do Pará, e o seu primeiro ciclo econômico, o ciclo do caucho. O jogo possui duas fases: a fase 1 que ocorre na área do Pontal (encontro dos rios Itacaiúnas e Tocantins), onde a missão será o reflorestamento com árvores de caucho; e a fase 2 que ocorre no encontro das ruas 27 de março e Quintino Bocaiuva, onde a missão será a construção de uma nova "Casa Marabá". Durante todo o jogo se terá como objetivo principal a obtenção de "bônus de informações". O processo de elaboração do jogo é descrito, destacando os aspectos educacionais e lúdicos, assim como os resultados da utilização do jogo pelos alunos de diversas turmas do $8^{0}$ ano do ensino fundamental, na disciplina estudos amazônicos, que faz parte da grade curricular das escolas do estado do Pará.

\section{Introdução}

Diversas tecnologias vêm sendo atualmente desenvolvidas para auxiliar o processo de ensino-aprendizagem, seja com o intuito de auxiliar diretamente o professor em suas atividades, seja para apoiar o aprendizado dos alunos. Aliando o espaço escolar com jogos digitais, pode-se transformar este espaço em um ambiente mais atrativo, agradável e prazeroso, permitindo que o educador alcance sucesso em sala de aula.

Os jogos educacionais se mostram ser um mecanismo útil para a educação, já que são ferramentas muito bem aceitas independentemente de classe social, gênero ou 
V Congresso Brasileiro de Informática na Educação (CBIE 2016)

Anais do XXII Workshop de Informática na Escola (WIE 2016)

idade do aluno, e em certos casos ser mais eficaz que a leitura de textos. [DUBIELA e BATTAIOLA, 2014].

A área de educação é atualmente uma das maiores consumidoras de produtos gamificados (que utiliza elementos de games como: mecânicas, estratégias e pensamentos), auxiliando o processo de aprendizagem de maneira mais lúdica, aumentando a motivação dos participantes [BEM, 2014].

Nesta perspectiva, a relevância educacional e social da presente pesquisa evidencia-se em virtude do objeto de estudo ser uma estratégia de ensino diferenciada, que utiliza um jogo educacional 3D, em terceira pessoa, no estilo RPG (Roleplaying Game) aventura, como prática pedagógica no processo de ensino-aprendizagem da disciplina de Estudos Amazônicos, que faz parte da grade curricular do ensino fundamental do estado do Pará.

Para a avaliação do projeto piloto, participaram 4 professores e 50 alunos de 3 turmas do $8^{\circ}$ ano (onde o tema histórico é tratado) do ensino fundamental da Escola Municipal e Estadual Anísio Teixeira, localizada na cidade de Marabá-PA. Calcula-se que a faixa etária dos jogadores será de 12 a 15 anos em condições normais.

Uma premissa básica que orientou o projeto do jogo educativo foi o uso do lúdico, ou seja, o estudante vai aprender brincando, onde a matéria de estudo é repassada ao aprendiz-jogador, através de "Bônus de Informações", enquanto esse avança nas fases do jogo. As informações contidas nos bônus são fatos históricos que marcaram a fundação da cidade, retirados do livro "História de Marabá", de Maria Virgínia Bastos de Mattos [MATTOS, 2013].

Além de tratar sobre a fundação da cidade, o jogo também apresenta os fatos relacionados ao seu primeiro ciclo econômico, o do caucho (árvore de borracha, hoje extinta na região). E coloca em foco a temática da sustentabilidade, onde o jogador terá como missão, o reflorestamento de uma área, com árvores de caucho. Um vídeo sobre o jogo se encontra disponível no link: https://www.dropbox.com/s/ondcdlhyzgsuqft/Video.mp4?dl=0

$\mathrm{Na}$ segunda seção, trataremos dos trabalhos correlatos. Na terceira seção apresentaremos o documento do game design: a temática do jogo, roteiro, cenários e personagens. Na quarta seção serão descritos os materiais e métodos utilizados, bem como sua implementação. Na quinta seção apresentamos as avaliações. Na sexta seção as considerações finais. Por fim, as referências bibliográficas encerram o artigo.

\section{Trabalhos Correlatos}

Nesta seção comentamos quatro jogos que tem como ponto principal o ensino de história baseado em games.

A "Revolta da Cabanagem" é um jogo de computador educativo cuja temática é o Movimento Cabano ocorrido no Pará no século XIX, a revolução é apresentada pelo uso de imagens, textos, animações, narrativas e o ambiente do jogo. $\mathrm{O}$ enredo segue a ordem cronológica dos fatos, e com os desafios impostos, torna-o atraente e motivador. O jogo tem 5 fases com a história bem distribuída entre elas [REIS et. al., 2008]. 
O "Laguna", narra os acontecimentos da retirada da Laguna, episódio da Guerra do Paraguai, que foi desenvolvido baseado nas premissas do construcionismo e com utilização de ferramentas de software livre. O objetivo do jogo é auxiliar no processo de ensino e aprendizagem de temas relacionados à História do Brasil, de uma forma atraente e divertida [MÜLLER et. al., 2007].

O "Regente" tem como temática principal a fase pós-independência do Brasil, com suas etapas divididas em algumas batalhas do período regencial, onde o país passava por uma transição política com diferentes correntes com suas particulares posições e ideologias [BARBOSA et. al., 2012]. O jogo tem o intuito de reforçar e auxiliar o ensino de História do Brasil e transmitir um pouco da cultura brasileira e indígena, explorando elementos do folclore e tradições regionais.

O "Projeto Game Ijiba: a saga quilombola", consiste no uso da computação gráfica e de uma ferramenta de modelagem, animação e produção de games, para produzir um jogo compacto, que visa dar suporte aos professores, para que os mesmos possam exemplificar as batalhas e as ações cotidianas dos membros das comunidades quilombolas para se proteger dos capitães do mato das fazendas das quais eram escravizados e assim melhorar a absorção e o desempenho dos discentes com a disciplina. Os professores poderão desenvolver suas aulas através de simulações de como eram essas lutas, feitas de modo ilustrativo, auxiliando no aprendizado e no raciocínio lógico. [ALVES et. al., 2015]

\section{O Projeto GAME Marabá}

\subsection{História}

O jogo tem como objetivo principal o aprendizado lúdico da história da fundação da cidade, através das aventuras de Velho Chico, espírito de Francisco Coelho da Silva (fundador de Marabá), que viaja no tempo do ano de 1906 (ano de sua morte) até o ano de 2015. E ao chegar ao Pontal, localizado no bairro Francisco Coelho, a margem do encontro dos rios Itacaiúnas e Tocantins, local de fundação da cidade, percebe as mudanças ocorridas com o passar do tempo, e que não existem mais árvores de caucho na região. Neste cenário ele terá como missão principal, plantar árvores de caucho. Com a finalização da missão, Velho Chico subirá o moro, chegando ao espaço de encontro das ruas 27 de março e Quintino Bocaiuvas, onde agora terá como missão principal, a construção da casa de aviamentos de cujo nome se originou o nome da cidade, a "Casa Marabá” [MATTOS, 2013].

\subsection{GDD (Documento de Game Design)}

O jogo está estruturado em duas fases:

1. Fase do Caucho: onde o jogador terá como missão obter 5 bônus de informações, e reflorestar o ambiente atual com 50 árvores de caucho. Como desafio deverá obter sementes, ao lutar e vencer 50 esqueletos de espíritos dos caucheiros.

2. Fase da Casa Marabá: onde se têm como missão obter 3 bônus de informações, e reconstruir uma nova "Casa Marabá". Como desafio deverá lutar e vencer 40 esqueletos de espíritos de guerreiros indígenas, que tentam impedir a criação da 
V Congresso Brasileiro de Informática na Educação (CBIE 2016)

Anais do XXII Workshop de Informática na Escola (WIE 2016)

"Casa Marabá", pois a sua construção contribuiu para a terrível diminuição da população indígena na região da cidade de Marabá.

Em todas as fases o jogador inicia com 100 pontos de vida, e sempre que é atingido pelos seus inimigos perde 10 pontos. Para recuperar pontos de vida, o jogador deverá se alimentar com comidas típicas da região, presentes nos cenários. Na parte superior das figuras 1 e 2 , se encontram os contadores de vida, de árvores e de sementes. $\mathrm{Na}$ figura 1, ainda não foi plantada nenhuma árvore, e na figura 2 já foram plantadas todas as 50 árvores.

\subsubsection{Cenários}

- Cenário da Fase 1: área do Pontal, encontro dos rios Itacaiúnas e Tocantins, onde se iniciou a fundação da cidade de Marabá (Figuras 1 e 2).

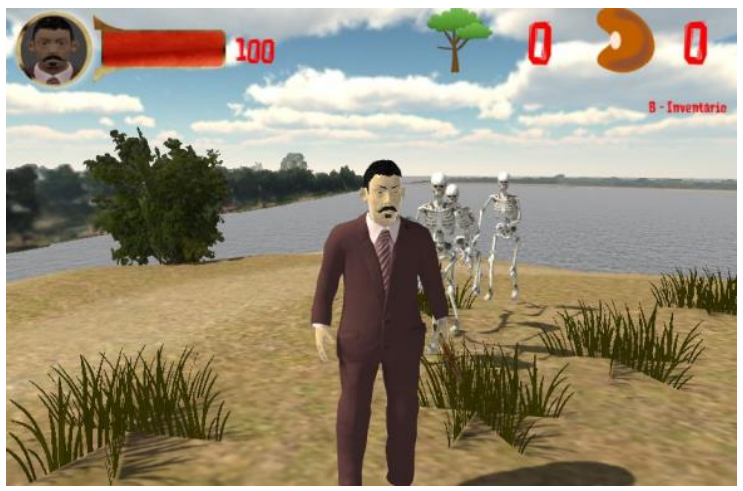

Figura 1. Cenário 1 com esqueletos

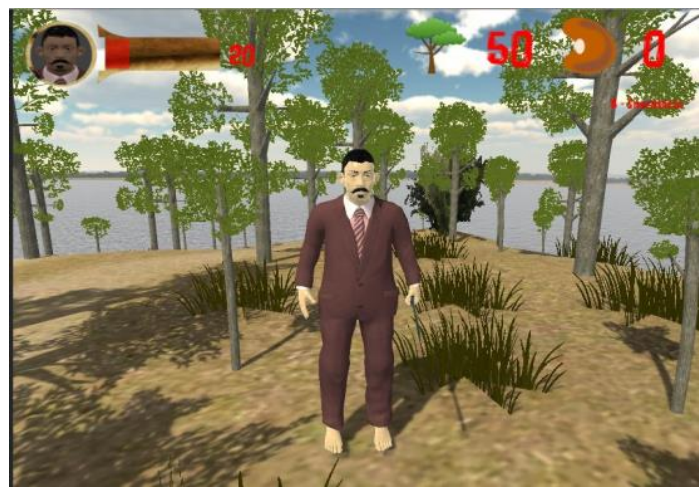

Figura 2. Cenário $1 \mathrm{com}$ árvores

- Cenário da Fase 2: encontro e início das ruas Quintino Bocaiuva e 27 de Março, primeiras ruas da cidade, no bairro Francisco Coelho (Figuras 3 e 4).

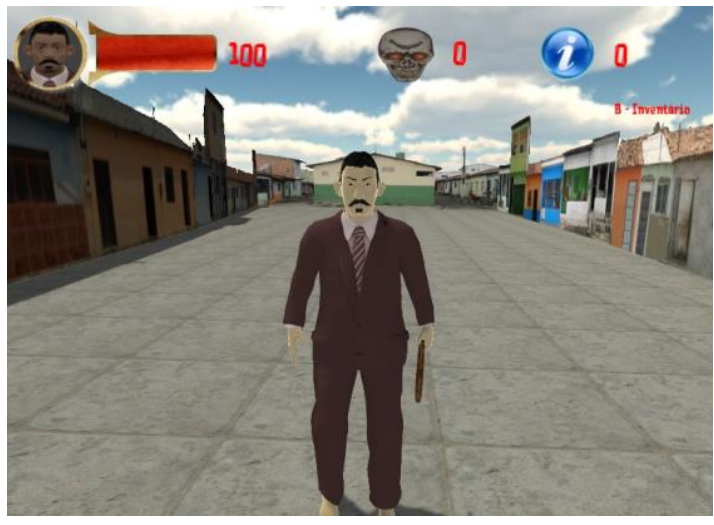

Figura 3. Cenário 2 com Velho Chico

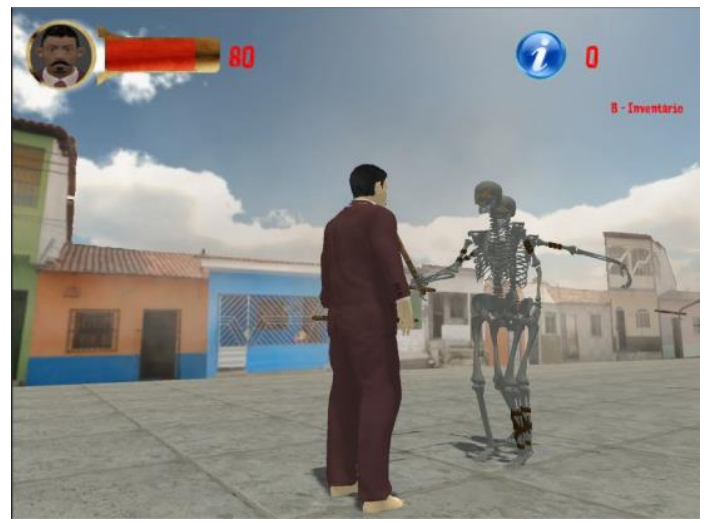

Figura 4. Cenário 2 com esqueletos

\subsubsection{Personagens}

- Velho Chico: Francisco Coelho da Silva trabalhou como seringueiro no Estado do Amazonas, onde conheceu o caucho. Instalou no Pontal, o comércio chamado "Casa Marabá". Seu espírito, o velho Chico (Figura 3) viaja no tempo do ano de 1906 ao ano de 2015 com a missão de obter bônus de informações, e mudar a paisagem atual do bairro Francisco Coelho, com o reflorestamento de árvores de caucho, e a fundação de uma nova Casa Marabá. 
- Espíritos dos Caucheiros: Esqueletos dos espíritos dos antigos exploradores de caucho, que tentam impedir o Velho Chico de reflorestar o Pontal com a plantação de árvores de caucho. (Figura 1).

- Espíritos dos Guerreiros Indígenas: Esqueletos dos espíritos dos antigos moradores indígenas (Figura 4) que tentam impedir o Velho Chico de reconstruir uma nova Casa Marabá, símbolo da colonização da região pelo homem branco.

\subsubsection{Itens}

- Armas: Velho Chico tem como armas de ataque/defesa uma bordunas e um facão.

- Sementes e Árvores: A cada esqueleto derrotado, se ganha uma semente de caucho que deverá ser plantada (Figura 2).

- Bônus de Vida: São comidas típicas da região (açaí, carne seca, peixe frito, chambaril) que ficam flutuando no cenário, e dão pontos de vida ao jogador.

- Bônus de Informação: A cada 10 esqueletos derrotados, o jogador ganha informações históricas sobre Marabá em forma de texto e áudio (Figura 5).

- Poder de Construção: Ao derrotar 40 esqueletos na fase 2, o jogador ganha o poder de construir uma nova "Casa Marabá" (Figura 6).

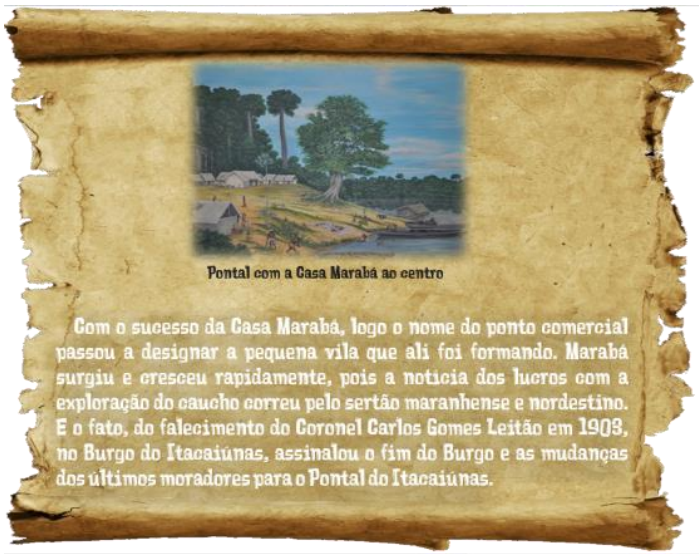

Figura 5. Bônus de Informação

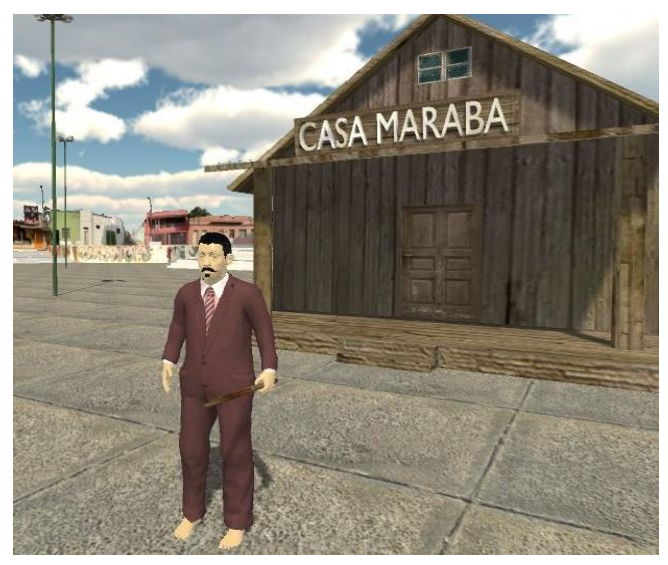

Figura 6. Casa Marabá

\section{Materiais e Métodos}

Apresenta-se a seguir, a metodologia e ferramentas utilizadas para construção do jogo.

\subsection{Materiais}

- Blender 2.77: é uma ferramenta que permite a criação de objetos e cenários 3D. Oferece funcionalidades completas para modelagem, renderização, animação, pós-produção, criação e visualização de conteúdo $3 \mathrm{D}$ interativo. É desenvolvido como 'Software Livre', e o seu código fonte está disponível sobre a licença GNU GPL [BLENDER, 2016].

- Gimp 2.8.14: é um programa de edição e criação de imagens para Windows, Mac e Linux. Sendo uma boa alternativa gratuita ao Photoshop e conta com uma 
série de ferramentas e recursos, como pincéis e efeitos para fotografias. Foi usado no tratamento das imagens usadas para produção de texturas dos cenários e modelos 3D [GIMP, 2016].

- MakeHuman 1.0.2: é um software open source que gera modelos humanoides em 3D. É escrito em C++ e Python [MAKEHUMAN, 2016]. Esta ferramenta foi utilizada na confecção do personagem principal do jogo, "Velho Chico", que após ser criado foi exportado para o Blender.

- Modelos 3D gratuitos: Os personagens Espíritos dos Caucheiros [FILHO, 2014], e Espíritos dos Guerreiros Indígenas [BLENDSWAP, 2016] são modelos $3 \mathrm{D}$ de esqueletos cedidos de forma gratuita para uso neste projeto, e que foram modificados para atender as necessidades do mesmo.

- Unity 3D: é uma game engine (motor) com licença gratuita para fins acadêmicos e que permite um processo mais rápido na criação de um jogo, já que implementa diversas funções básicas e até algumas mais avançadas para o desenvolvimento completo. Além de uma ferramenta extremamente poderosa para criação de games de todos os tipos, para várias plataformas diferentes. Essa ferramenta permite a utilização de scripts, tanto na linguagem C\# como em JavaScript, para adicionar lógica ao seu game [UNITY, 2016]. Tal ferramenta foi utilizada para integração de todos os elementos que compõem este jogo, como personagens, cenários, músicas, sons, câmeras, iluminação, e outros modelos 3D.

\subsection{Métodos}

- Modelagem: O personagem Velho Chico foi modelado no Makehuman, onde ganhou aparência física, esqueleto, corpo e vestimenta. Os cenários são compostos de vários elementos, como casas e mansões com arquitetura antiga, formações montanhosas, vegetações, blocos e rios, e foi modelado com uso do Blender.

- Implementação: Após finalização da modelagem de todos os elementos que compõem o jogo através do Blender, estes então são exportados no formato blend e importados no Unity, onde são atribuídas as ações, controláveis ou não, através de funções e scripts, iluminação, câmera, isto é, a visão do personagem, e outros elementos finais.

- Testes e Validação: As avaliações constituíram na participação de alunos do $8^{\circ}$ ano do ensino fundamental, em uma simulação do jogo educacional dentro de um laboratório de informática, onde os alunos ficaram livres para utilizar o jogo e interagir com os colegas de turma.

\section{Avaliação}

Para execução do processo avaliativo foi feito um experimento no laboratório de informática da Escola Anísio Teixeira, onde participaram 50 alunos, de 3 turmas do $8^{\circ}$ ano do ensino fundamental (Figura 7). 

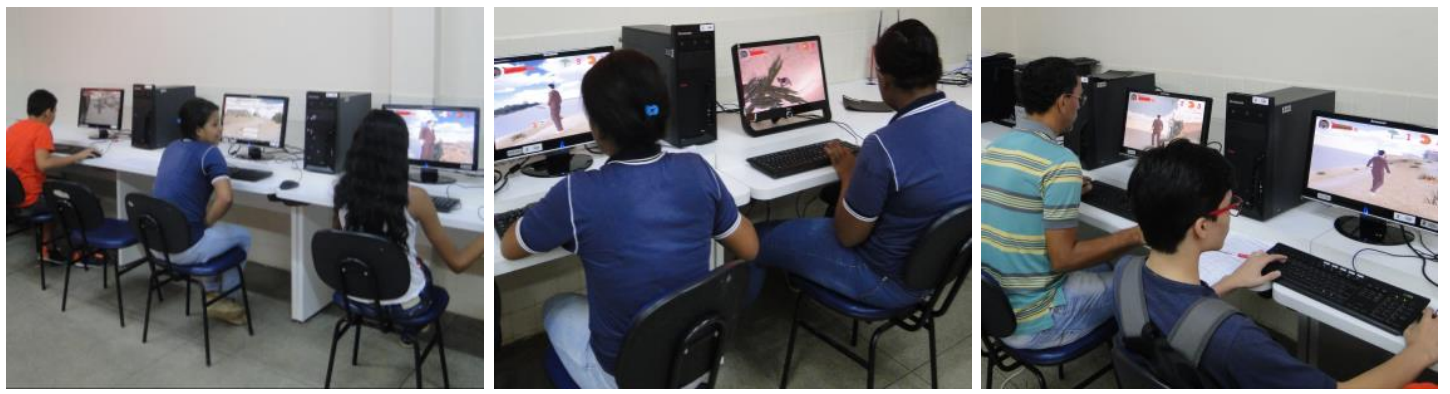

Figura 7. Laboratório de Informática

Para coleta dos dados foi utilizado um questionário com 22 questões, que segue o modelo implementado por Chritiane Gresse Von Wangenheim utilizado em [SAVI, 2011].

Os resultados da avaliação do jogo são apresentados a seguir, divididos em três sub escalas (motivação, experiência do usuário e aprendizagem). $\mathrm{O}$ avaliador tinha 5 opções de respostas para cada questão, numa escala de "Discordo Totalmente" a "Concordo Totalmente".

\subsection{Motivação}

O item motivação é dividido em 4 aspectos: Satisfação (questões 1 e 2), Confiança (questões 3 e 4), Relevância (questões 5 e 6), e Atenção (questões 7 e 8). De modo geral foi possível observar que o jogo teve um efeito positivo na motivação dos alunos em grande parte das questões, como pode ser observado no gráfico de frequência a seguir (Figura 8).

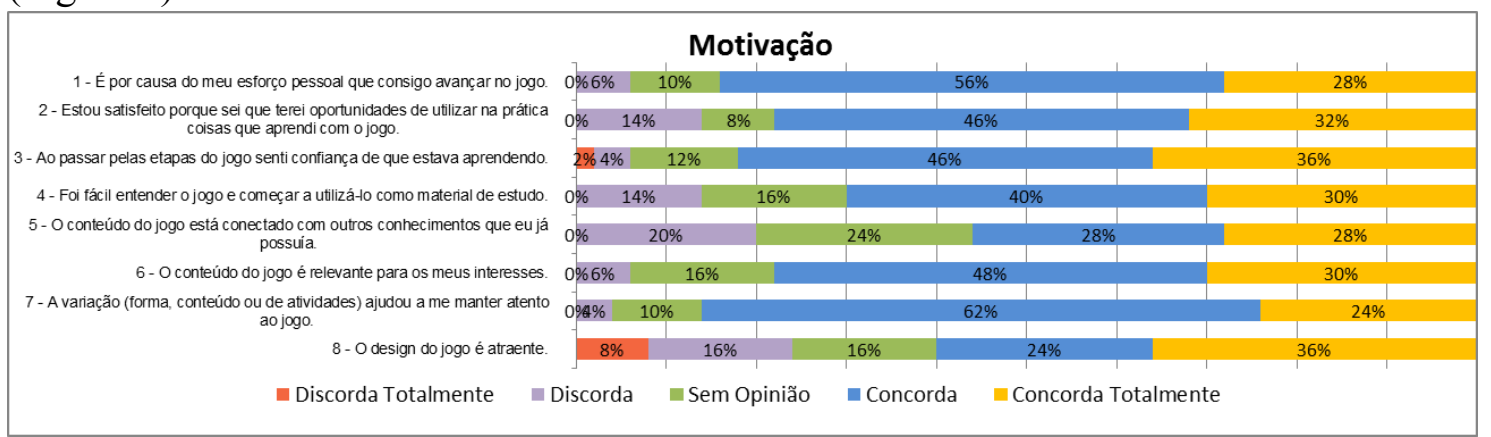

Figura 8. Dados do questionário referentes aos itens de motivação

É possível perceber uma maior concentração nas notas "Concordo Totalmente" e "Concordo" em todas as questões. A média total dos alunos que atribuíram as notas foi de 75\%. As notas "Discordo" e "Discordo Totalmente" tiveram a média de 12\%. E "Sem Opinião" foi de 13\%.

Ainda é possível verificar que as questões 1 e 7 obtiveram as maiores porcentagens de notas "Concordo Totalmente" e "Concordo" na escala motivação. E que as questões 5 e 8 obtiveram a maior porcentagem de notas "Discordo Totalmente" e "Discordo"

Analisando individualmente a avaliação positiva dos aspectos, constatamos que: satisfação teve média de $81 \%$, confiança teve $76 \%$, relevância teve $67 \%$, e atenção teve $73 \%$. 
V Congresso Brasileiro de Informática na Educação (CBIE 2016)

Anais do XXII Workshop de Informática na Escola (WIE 2016)

\subsection{Experiência do Usuário}

O item experiência do usuário é dividido em 5 aspectos: Competência (questões 9 e 10), Diversão (questões 11, 12 e 13), Desafio (questões 14 e 15), Interação Social (questões 16 e 17), e Imersão (questões 18 e 19 ). Pode-se considerar que o jogo de um modo geral proporcionou uma experiência positiva nos alunos, como pode ser observado no gráfico de frequência a seguir (Figura 9).

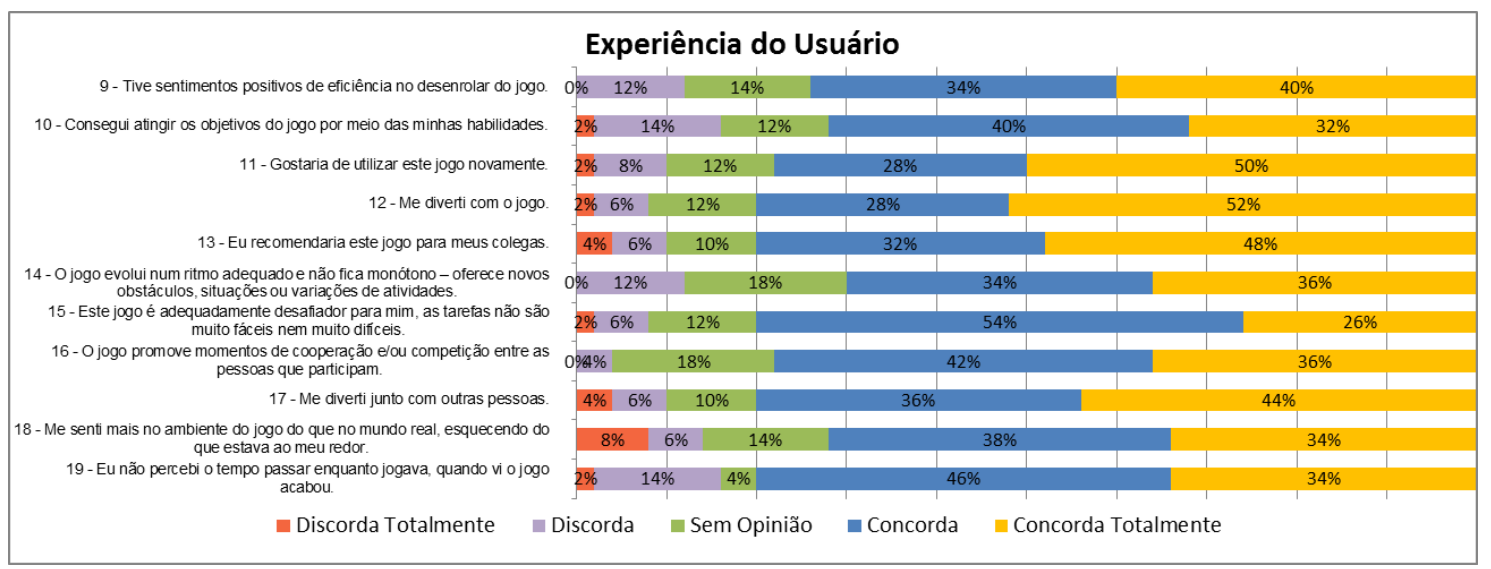

Figura 9. Dados do questionário referentes aos itens de experiência do usuário

As notas "Concordo Totalmente" e "Concordo" tiveram uma maior porcentagem em todas as questões. A média total dos alunos que atribuíram as notas foi de $77 \%$. As notas "Discordo" e "Discordo Totalmente" tiveram a média de 11\%. E "Sem Opinião" teve $12 \%$.

Verifica se que as questões 12, 13, 15, 17 e 19 obtiveram as maiores porcentagens de notas "Concordo Totalmente" e "Concordo", cada uma tendo total de $80 \%$ de avaliação positiva na escala experiência do usuário. E que as questões 10 e 19 obtiveram a maior porcentagem de notas "Discordo Totalmente" e "Discordo", cada uma tendo total de $16 \%$ de avaliação negativa.

Analisando individualmente a avaliação positiva dos aspectos, constatamos que: competência teve média de $73 \%$, diversão teve $79 \%$, desafio teve $75 \%$, interação social teve $79 \%$, e imersão teve $76 \%$.

\subsection{Aprendizagem}

O item aprendizado é dividido em 2 aspectos: Dimensão aprendizagem de curto termo (questões 20 e 21), e Dimensão aprendizagem de longo termo (questão 22). Em um nível geral nota-se que na percepção dos alunos, o jogo contribuiu para o aprendizado de assuntos referentes a fundação da cidade de Marabá, e o ciclo econômico do caucho, como pode ser observado no gráfico da (Figura 10).

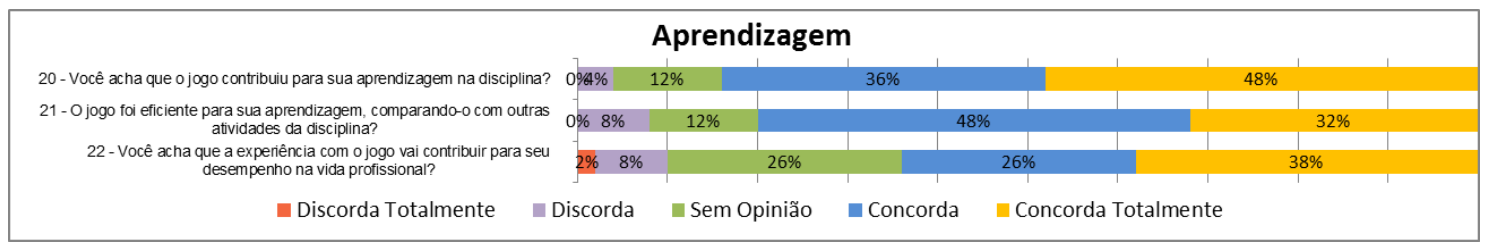

Figura 10. Dados do questionário referentes aos itens de aprendizagem 
Na dimensão aprendizagem de curto termo, $84 \%$ dos alunos concordam que o jogo trouxe contribuições na aprendizagem (questão 20) e deram notas "Concordo Totalmente" e "Concordo". E 80\% consideram o jogo eficiente em comparação com outras atividades usadas atualmente para passar conteúdos inerentes a fundação de Marabá (questão 21).

$\mathrm{Na}$ dimensão aprendizagem de longo termo, 64\% de alunos atribuíram notas "Concordo Totalmente" e "Concordo" ao item referente a experiência com o jogo em sua vida profissional (questão 22).

A questão 22 foi a que apresentou a maior porcentagem de notas "Discordo Totalmente" e "Discordo", tendo total de 10\% de avaliação negativa. E a mesma questão foi a que teve a maior porcentagem de todo o questionário avaliativo de notas "Sem Opinião", com 26\%. O que mostra uma incerteza dos avaliadores em prever o papel do jogo educativo em sua futura vida profissional.

De modo geral em toda a avaliação os aspectos de satisfação (81\%) e dimensão aprendizagem de curto termo (84\%) foram os aspectos melhor avaliados pelos alunos. $\mathrm{O}$ que comprova o alcance do objetivo principal deste projeto, que é ensinar de forma mais agradável, e com plena satisfação e envolvimento do aluno.

Com os resultados obtidos neste primeiro experimento já foi possível perceber a importância que este jogo poderá conseguir através de sua estratégia de informação. Esta avaliação foi de extrema importância, pois foi através dela que foi implementado melhorias no jogo baseado nas sugestões dos alunos ao longo do experimento visando uma efetividade cada vez maior no processo de ensino-aprendizagem.

\section{Considerações Finais}

Conforme exposto, este projeto contribuirá para a melhoria e dinamicidade das aulas da disciplina de Estudos Amazônicos, sobretudo a história da cidade de Marabá-PA, onde através desse projeto, o aluno terá interação com os diversos personagens e cenários nos quais poderão similar situações históricas, assim como também trabalhar o raciocínio lógico que o auxiliará em muitas outras disciplinas.

Pode-se dizer que através da utilização deste jogo os alunos podem vislumbrar possibilidades de conhecimento do passado, estudar fatos e documentos e estabelecer relações com o seu presente. Inserindo os estudantes no processo de construção da sua aprendizagem.

Neste projeto, a Escola Anísio Teixeira foi selecionada como escola piloto e contribuiu para o desenvolvimento e avaliação da ferramenta, e com a finalização do projeto piloto, todas as outras escolas de ensino fundamental de Marabá poderão utilizar o jogo em seus laboratórios de informática.

Com uma avaliação positiva de mais de $75 \%$ de aprovação na maioria das questões, a utilização dessa ferramenta será um grande aliado na transmissão de conteúdos educacionais, transformando as aulas que, por muitas vezes aparentemente monótonas e complicadas, em dinâmicas e claras. 
V Congresso Brasileiro de Informática na Educação (CBIE 2016)

Anais do XXII Workshop de Informática na Escola (WIE 2016)

Como trabalhos futuros se propõe o desenvolvimento da terceira fase do jogo que trata sobre o ciclo econômico da Castanha do Pará, dando assim prosseguimento a história de fundação da cidade de Marabá.

\section{Referências}

ALVES, L., COSTA, G., CRUZ, V., PACHECO, E., DOS SANTOS, M.. Projeto Game Ijiba: a saga quilombola. REVISTA DE COMPUTAÇÃO -- ISSN 2446-7812, América do Norte, 1, mai. 2015. Disponível em: http://periodicos.uesb.br /index.php/rc/article/view/4645. Acesso em: 28 Abr. 2016.

BARBOSA, J. G. G.; YAMAMOTO, F. S.; PARIENTE, C. A. B. 2012. Regente: Jogo de aventura para ensino de História e cultura folclórica brasileira. SBGAMES.

BEM, R. F. S., 2014. "Projeto ludus: uma metodologia gamificada de gerenciamento de projetos" 2014. 73 f. Dissertação (Mestrado em Design) - Departamento de Design, Universidade Federal de Pernambuco, Recife. 2014.

BLENDER, 2016. Blender 2.77a. [online] Disponível em: https://www.blender.org/. Acesso em: 28 Abr. 2016.

BLENDSWAP, 2016. Skeleton. [online] Disponível em: http://www.blendswap.com/ blends/view/56189/. Acesso em: 28 Abr. 2016.

DUBIELA, R. P.; BATTAIOLA, A. L., 2014. A utilização de dispositivos móveis como plataformas para aplicações educacionais gamificadas. SBGAMES.

FILHO, M. R.; Silva F A. C.; Soares, T. P.; Ribeiro, J. L. O.; Silva, C. L. S.; Melo, A. C. 2014. Jogo Eletrônico com Informação sobre Espaços e Monumentos Públicos Urbanos. SBGAMES

GIMP, 2016. Gimp 2.8.16. [online] Disponível em: https://www.gimp.org/. Acesso em: 28 Abr. 2016.

MAKEHUMAN, 2016. MakeHuman 1.0.2. [online] Disponível em: http://www.makehuman.org/index.php. Acesso em: 28 Abr. 2016.

MATTOS, Maria Virginia Bastos de. História de Marabá. 2. ed. Revisada e aumentada, Fundação Casa da Cultura de Marabá, 2013.

MÜllER, R. M.; CAVAlCANTE, G. D.; SANTOS, L. A. dos. 2007. Laguna Aprendendo sobre a Guerra do Paraguai com jogo educativo. WIE-SBC.

REIS F. V.; DAMASCENO, R. R.; SILVA F.; RIBEIRO, F. M. 2008. Jogo educativo sobre a Revolução da Cabanagem - Fase Pré-Revolucionária. WIE-SBC.

SAVI, Rafael: Avaliação de jogos voltados para a disseminação do conhecimento [tese] / Rafael Savi; orientadora, Vânia Ribas Ulbricht. - Florianópolis, SC, 2011. (dissertação doutorado)

UNITY, 2016. Unity 3d [online] Disponível em: http://www.unity3d.com/unity. Acesso em: 28 Abr. 2016. 